\title{
Characterization of deep-level defects in GaNAs/GaAs heterostructures grown by APMOVPE
}

\author{
Łukasz GelczuK ${ }^{1, *}$, Maria Dąbrowska-Szata ${ }^{1}$, Beata Ś Siana ${ }^{1}$, Damian Pucicki ${ }^{1}$, \\ DAMian RADZIEWICZ ${ }^{1}$, KrZYSZTOF Kopalko ${ }^{2}$, MAREK TŁaCZAŁA ${ }^{1}$ \\ ${ }^{1}$ Faculty of Microsystem Electronics and Photonics, Wroclaw University of Science and Technology, Janiszewskiego 11/17, \\ 50-372 Wroclaw, Poland \\ ${ }^{2}$ Institute of Physics, Polish Academy of Science, al. Lotnikow 32/46, 02-668 Warsaw, Poland
}

Conventional deep level transient spectroscopy (DLTS) and high-resolution Laplace DLTS techniques were used to study electrical properties of deep-level defects in dilute GaNAs epitaxial layers grown by atmospheric-pressure metalorganic vapourphase epitaxy (APMOVPE) on the GaAs substrate. Three samples with nitrogen concentrations of $1.2 \%, 1.6 \%$ and $2.7 \%$ were investigated. In DLTS and LDLTS spectra of the samples, four predominant electron traps were observed. On the basis of the obtained electrical parameters and previously published results, one of the traps was associated with N-related complex defects, while the other traps with common GaAs-like native defects and impurities, called EL6, EL3 and EL2.

Keywords: GaNAs; dilute nitrides; deep-level defects; DLTS; LDLTS; APMOVPE

(C) Wroclaw University of Science and Technology.

\section{Introduction}

In the last two decades, the III-V group semiconductors diluted with nitride $(\mathrm{N})$, as GaNAs or GaInNAs alloys, have attracted a great deal of attention due to their unique properties and potential applications in modern optoelectronic devices, especially high efficiently multi-junction solar cells (MJ) $[1,2]$, infrared lasers [3, 4] or photodetectors [5]. A scientific interest of this class of materials is connected with facility and elasticity in formation of their electrical and optical properties. The change of composition of the III-V-N compounds makes possible modification of their band gap in a wide energy range and lattice matching of the unit cells of different layers in multilayer structures, leading in consequence to new properties of designed devices. In particular, introduction of small amounts of $\mathrm{N}$ into GaAs drastically decreases band gap energy of the GaNAs structure and also reduces the lattice parameters of the crystal. Therefore GaNAs is used for strain compensation in

*E-mail: lukasz.gelczuk@pwr.edu.pl different heterostructures. For example, nitrogen compensates indium-induced compressive strain in the GaInAs alloy, making possible growing of GaInNAs layers lattice matched to GaAs substrates and simultaneously reducing its band gap energy down to about $1 \mathrm{eV}$ or even beyond, what is favorable for long-wavelengths applications [3, 4].

Despite of a huge progress in technology of III-V-N dilute nitrides-based devices in the last two decades, regardless of the technique of epitaxial growth of GaNAs and GaInNAs (MBE or MOVPE), these devices have still exhibited less than the optimum performance due to relatively poor material quality. The presence of nitrogen as well as technological limitations of these materials involve generation of many structural defects, especially those associated with incorporation of $\mathrm{N}$ atoms into the crystal lattice, which can significantly affect deterioration of many electrical and optical properties of the material [6-8]. Electrically active deep-level defects in the band gap can influence the density of charge carriers, their diffusion lengths, mobility and lifetime or efficiency of luminescence, leading finally to device degradation. 
Therefore, the fundamental goal is to relate electrical properties of defects with the properties of III-V-N compounds. Although, for such dilute nitride compounds many deep-level studies have been reported in the literature so far, there are still some open questions. In particular, investigation of the emergence of deep-level defects in relation to the growth conditions and the nitrogen incorporation in the samples grown by APMOVPE method may be a matter of interest for the intended device applications. The aim of our investigations is to understand the physics of defects in these alloys and to optimize their growth conditions by APMOVPE and post-growth annealing procedures, in order to improve their structural and optical quality, as well as to reduce the defect density.

In this paper, we report electrical characterization of deep-level defects in APMOVPE grown undoped GaNAs/GaAs heterostructures, with different $\mathrm{N}$ contents (ranging from $1.2 \%$ to $2.7 \%$ ) using conventional deep level transient spectroscopy (DLTS) and high resolution Laplace DLTS (LDLTS). The DLTS temperature spectra revealed several closely spaced deep traps in a lowtemperature part of the spectrum $(<300 \mathrm{~K})$ and one trap in a high-temperature range $(>300 \mathrm{~K})$. Combination of conventional DLTS and high resolution LDLTS techniques enabled us to specify the fundamental parameters of the traps (i.e. thermal activation energy, capture cross section and concentration), as well as to indicate their possible origin in the samples. The main objective of this study is to provide essential information for optimizing growth conditions and thus for improving quality of the GaNAs material as well as to explain the effect of deep-level defects on the performance and parameters of future devices.

\section{Experimental}

The GaNAs epitaxial layers were grown on Si-doped $\left(\sim 10^{18} \mathrm{~cm}^{-3}\right)$ n-GaAs substrates using an atmospheric pressure metalorganic vapour phase epitaxy (APMOVPE) system, equipped with AIX200 R\&D AIXTRON horizontal reactor. Trimethylgallium (TMGa), arsine $\left(\mathrm{AsH}_{3}: 10 \%\right.$ mixture in $\mathrm{H}_{2}$ ) and tertiarybutylhydrazine (TBHy) were used as grow precursors and they were transported by passing a high purity $\mathrm{H}_{2}$ through the bubblers. The undoped heterostructures consisted of a $450 \mathrm{~nm}$ thick undoped GaAs buffer layer and of about $300 \mathrm{~nm}$ thick GaNAs epitaxial layer. The measured background net doping concentration of the GaNAs layer was of about $1.5 \times 10^{16} \mathrm{~cm}^{3}$. All the epitaxial layers were grown at the same temperature equal to $566{ }^{\circ} \mathrm{C}$, which was determined from our earlier studies as the optimal value for the efficient nitrogen incorporation into GaAs, without considerable degradation of the structural quality [9]. The other stable parameters of the growth process were: the arsine flow rate $\mathrm{V}_{\mathrm{AsH} 3}=$ $50 \mathrm{~mL} / \mathrm{min}$ for GaNAs and $300 \mathrm{~mL} / \mathrm{min}$ for $\mathrm{GaAs}$ and the total hydrogen flow rate through the saturator with $\mathrm{TM}_{\mathrm{Ga}}$, equal to $\mathrm{V}_{\mathrm{H} 2 / \mathrm{TMGa}}=9.6 \mathrm{~L} / \mathrm{min}$. All the samples were grown solely with the change of the hydrogen flow through the saturator with TBHy in the range of $\mathrm{V}_{\mathrm{H} 2 / \mathrm{TBHy}}=1500 \mathrm{~mL} / \mathrm{min}$ to $3000 \mathrm{~mL} / \mathrm{min}$. It enabled us to analyse the efficiency of nitrogen incorporation as a function of the flow rate $\mathrm{V}_{\mathrm{H} 2 / \mathrm{TBHy}}$. It should be mentioned that investigated samples were not annealed after the growth process. DLTS investigations of the influence of the annealing process on the properties and concentration of defects will be the subject of future studies.

Structural properties and composition of the $\mathrm{GaN}_{\mathrm{x}} \mathrm{As}_{1-\mathrm{x}} / \mathrm{GaAs}$ heterostructures were analyzed on the basis of XRD diffractograms and reciprocal space mapping by means of high-resolution X-ray diffraction (HRXRD). The results of these studies were reported previously [9]. The HRXRD measurements revealed some deterioration of structural quality of the GaNAs epitaxial layers compared to the GaAs substrate, by evident lowering of the reflex intensity and its broadening. Furthermore, a change of the reflex position as a function of the diffraction angle indicated a change of the lattice constant value and also enabled us to determine composition of the layers. In this paper, three samples with $1.2 \%, 1.6 \%$ and $2.7 \%$ nitrogen contents were investigated. The band gap energies of these samples, as measured by contact electroreflectance 
(CER) and confirmed by calculations according to the band anticrossing (BAC) model [10] are equal to about $1.22 \mathrm{eV}, 1.18 \mathrm{eV}$ and $1.08 \mathrm{eV}$, respectively.

Electrical characteristics of the films were measured on the Au Schottky barrier diodes (SBDs), $0.8 \mathrm{~mm}$ in diameter (the diode area was of $0.5 \mathrm{~mm}^{2}$ ), deposited in vacuum through a shadow mask by electrolitography technique on the top side of the samples. Prior to the SBD formation, the AuGe ohmic contacts were deposited on the whole backside and then the annealing was performed at $350{ }^{\circ} \mathrm{C}$ in $\mathrm{Ar}$ atmosphere for 5 minutes. The quality of the SBDs was verified by currentvoltage (I-V) and capacitance-voltage (C-V) measurements. The I-V measurements were performed with 2601A Keithley SMU instrument, while CV measurements with Boonton 7200 capacitance bridge. Deep-level defects were characterized by means of conventional DLTS as well as highresolution Laplace DLTS experiments.

\section{Results and discussion}

Fig. 1 shows the $\mathrm{I}-\mathrm{V}$ and $\mathrm{C}-\mathrm{V}$ characteristics of the GaNAs/GaAs samples recorded at $300 \mathrm{~K}$. All the samples revealed good rectifying properties, suitable for the principal studies on deeplevel defects with the use of DLTS method. The I-V characteristics provided the values of the series resistance (10 $\Omega$ to $50 \Omega$ ) and the ideality factor (1.8 to 2.0$)$. From the $\mathrm{C}-\mathrm{V}$ characteristics, a free carrier concentration of the unintentionally n-type doped GaNAs epitaxial layers was calculated at about $1 \times 10^{16} \mathrm{~cm}^{3}$ to $3 \times 10^{16} \mathrm{~cm}^{3}$. Concentration depth profiles (inset of Fig. 1b) show that the background doping concentration is almost uniformly distributed over the depth of the GaNAs epitaxial layers and slightly increases toward the GaAs buffer layer. Moreover, the builtin voltage was determined in the range of $1.7 \mathrm{~V}$ to $2.0 \mathrm{~V}$. The other details concerning basic electrical properties of the studied diodes were given in the literature [11]. From these electrical measurements, we estimated that at a reverse bias of $-2 \mathrm{~V}$, the space charge region is mostly located in the GaNAs epitaxial layer, however, the DLTS signal coming from the GaAs buffer layer is also expected. Accordingly, the standard bias conditions: reverse voltage $\left(\mathrm{V}_{\mathrm{R}}\right)-2 \mathrm{~V}$ and filling pulse voltage $\left(\mathrm{V}_{\mathrm{P}}\right)$ of $0 \mathrm{~V}$ were used for the DLTS measurements. A width of the filling pulse $\left(t_{p}\right)$ was set to $50 \mu \mathrm{s}$ and the emission rate window $\left(e_{n}\right)$ was equal to $20 \mathrm{~s}^{-1}$. The DLTS temperature spectra were measured in the $77 \mathrm{~K}$ to $480 \mathrm{~K}$ temperature range and analyzed separately in low- (below $300 \mathrm{~K}$ ) and high-temperature ranges (above $300 \mathrm{~K}$ ), due to considerable differences in the amplitudes of DLTS peaks observed in these two regions.
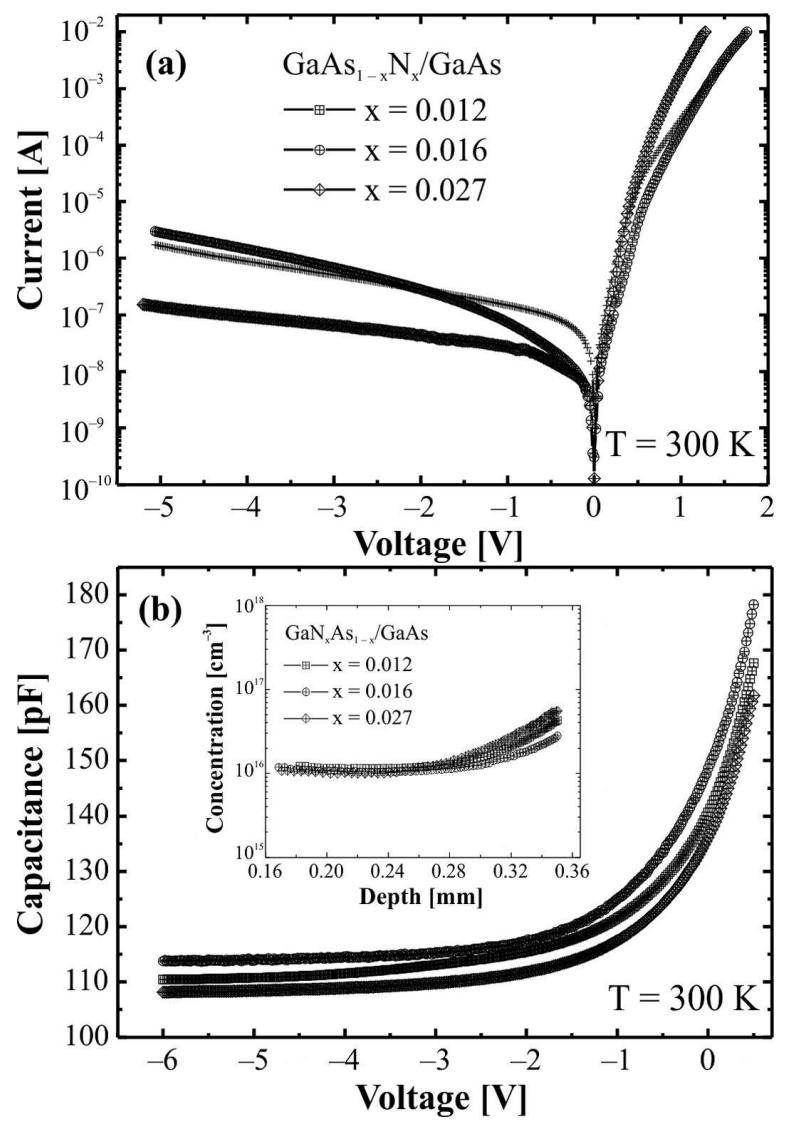

Fig. 1. (a) Current-voltage and (b) capacitance-voltage characteristics recorded at $300 \mathrm{~K}$ for all studied samples. In the inset of (b) background doping concentration vs. depth profiles are plotted.

\subsection{Low-temperature DLTS spectra}

Fig. 2 presents low-temperature DLTS spectra for all the studied GaNAs/GaAs samples. In this range and for the selected measurement conditions, 
a broad and positive DLTS-line signal is observed. In our system, the positive signal indicates that the peaks are correlated with thermal emission of majority carriers from deep levels. It is generally accepted that the majority peaks (traps) are those for which the capacitance transients are increasing function of time, whereas minority peaks manifest themselves by decreasing capacitance transient [12]. According to this statement, in the case of DLTS, a positive signal corresponds to majority traps while a negative one to minority traps.

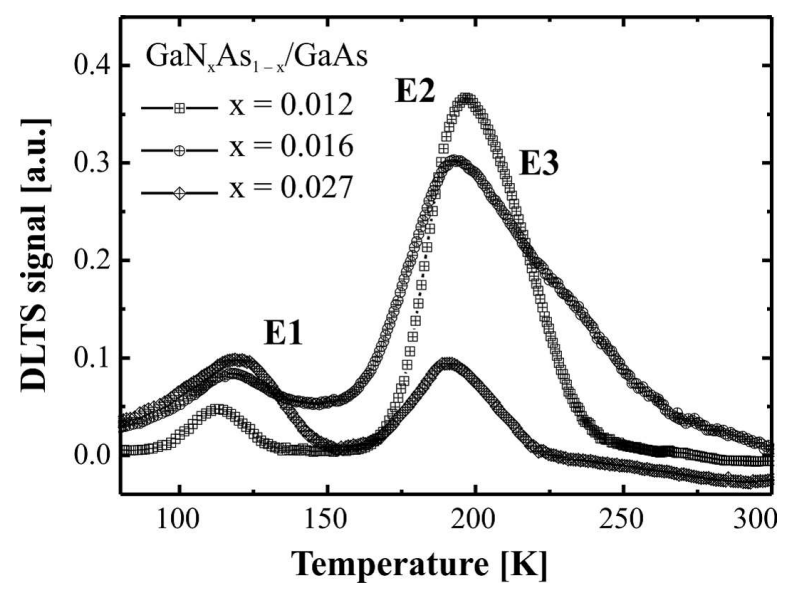

Fig. 2. Low-temperature DLTS spectra obtained for the $\mathrm{GaN}_{\mathrm{x}} \mathrm{As}_{1-\mathrm{x}} / \mathrm{GaAs}$ heterostructures with different nitrogen contents $(\mathrm{x})$ at a reverse bias voltage $\left(\mathrm{V}_{\mathrm{R}}\right)$ of $-2 \mathrm{~V}$, a filling pulse voltage $\left(\mathrm{V}_{\mathrm{P}}\right)$ of $0 \mathrm{~V}$, an emission rate window $\left(\mathrm{e}_{n}\right)$ of $20 \mathrm{~s}^{-1}$, and a filling pulse width $\left(\mathrm{t}_{\mathrm{p}}\right)$ of $50 \mathrm{~s}$.

First of all, we should answer the question whether the holes or electrons are the majority carriers observed in the DLTS measurements of our samples. It is generally known that while the undoped GaAs is usually n-type, a dilute GaNAs can be p-type or n-type, depending on the growth conditions and the type of elemental sources used in different growth techniques. The results presented in the literature indicate that as-grown, unintentionally doped GaNAs grown by MOVPE [13, 14] or MBE [15] is usually p-type, however for example a CBE growth can result in the n-type GaNAs material [16]. It has been speculated that this $p$ type background doping is a result of unintentional carbon contaminations [1, 17, 18]. Further confusing matter is the fact that annealing can strongly change both the carrier concentration and type in nitrogen diluted III-V materials. These changes are probably related to the hydrogen passivation of background carbon acceptors or even their dissociation from carbon upon annealing, but the existence of other types of defects that can contribute to the background carrier concentration cannot be excluded [1, 17, 19]. In the present studies, the TBHy is used as a source of nitrogen in the growth of dilute GaNAs and it could be also the additional source of carbon contaminations, causing ptype doping in the epitaxial layer. Nevertheless, although the undoped epitaxial layers were grown on the Si-doped $n+-G a A s$ substrate, we observed only a majority carriers signal in DLTS spectra shown in Fig. 2, thus the layers are in fact slightly ntype. If a p-n junction existed, both the positive and negative signal (dependent on the bias conditions) would be observed in DLTS measurements. It should be noticed yet that after annealing of similar GaNAs/GaAs samples we actually observe the DLTS signal coming from both hole and electron traps [20]. It has been concluded that the existence of the acceptor-like defects in MOVPE-grown samples could be related to activation of carbon impurities or reduction of hydrogen impurities density after annealing. These results strongly suggest that post-growth annealing clearly influences the electrical properties of the GaNAs layers grown at low temperatures $\left(566{ }^{\circ} \mathrm{C}\right.$ in our case) by means of APMOVPE technique. Both the electron and hole traps were also observed in undoped GaNAs/GaAs triple quantum well structures after annealing [21]. Finally, in the present study we correlated the positive DLTS signal with the existence of only electron traps in the as-grown and undoped GaNAs/GaAs heterostructures grown by APMOVPE.

Furthermore, a broad DLTS-line suggests that deep levels, giving rise to this signal, can be actually a continuous distribution of deep level states or groups of closely spaced discrete energy levels within the band gap. The positive DLTS signal observed for all studied samples in the $100 \mathrm{~K}$ to $300 \mathrm{~K}$ temperature range is in fact a sum of at least three overlapping peaks originating from three different electron traps, labeled by us 
tentatively as E1, E2 and E3. In order to resolve the closely spaced defect levels, high-resolution Laplace DLTS (LDLTS) was applied. The LDLTS technique is a powerful tool for thermal emission studies, because of its significantly improved spectral resolution compared to a conventional DLTS technique [22]. In case of ideal conditions, Laplace DLTS can resolve defect levels with emission rates differing by a factor of 2. Exemplary Laplace DLTS spectra, shown in Fig. 3 for one of the samples $(1.6 \%$ of $\mathrm{N})$, clearly demonstrate a high resolution of this technique, making possible to resolve all the peaks detected by conventional DLTS. In Fig. 3, one can also observe a distinct evolution of particular peak positions on increasing temperature of the measurement, i.e. the peaks E1 and E2 move towards higher emission rates, if the temperature increases. Moreover, when the temperature reaches $210 \mathrm{~K}$, another peak E3 reveals, while peak E1 disappears from the LDLTS spectrum.

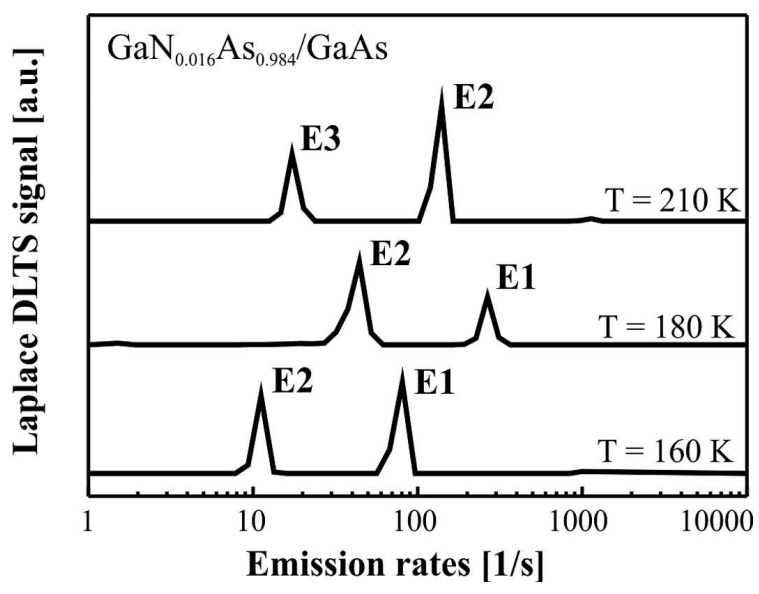

Fig. 3. Exemplary Laplace DLTS spectra of the $\mathrm{GaN}_{0.016} \mathrm{As}_{0.984} / \mathrm{GaAs}$ structure, taken at $160 \mathrm{~K}$, $180 \mathrm{~K}$ and $210 \mathrm{~K}$ for similar experimental conditions as those of conventional DLTS.

The activation energy $\left(\mathrm{E}_{\mathrm{a}}\right)$ and apparent capture cross-section $\left(\sigma_{\mathrm{a}}\right)$ of the traps can be extracted from the slope and intersection of the Arrhenius plot of $\ln \left(e_{n} / T^{2}\right)$ vs. $1000 / T$, respectively, where $e_{n}$ is the carrier emission rate from deep level at temperature $\mathrm{T}$. It follows from the detailed balance equation of the emission rate according to the formula [12]:

$$
e_{n}=\sigma_{a} v_{t h} N_{C} \exp \left[-E_{a} / k_{B} T\right]
$$

where $v_{\text {th }}$ is a thermal velocity of electrons, $N_{C}$ is an effective density of states in the conduction band and $\mathrm{k}_{\mathrm{B}}$ is the Boltzmann's constant. In case of electron traps, activation energy $E_{a}$ determines a deep energy level position $\left(\mathrm{E}_{\mathrm{T}}\right)$ in the band gap in relation to the conduction band edge $\left(\mathrm{E}_{\mathrm{C}}\right)$, according to the relationship $\mathrm{E}_{\mathrm{a}}=\mathrm{E}_{\mathrm{C}}-\mathrm{E}_{\mathrm{T}}$. Exemplary Arrhenius plots of the three traps observed in low temperatures for the sample with $1.6 \%$ of $\mathrm{N}$, are shown in Fig. 4. For comparison, the results obtained by conventional DLTS (crossed points) as well as highresolution Laplace DLTS (open points) analysis were presented. For conventional analysis, the Arrhenius plots were obtained by measuring a shift in the DLTS temperature peak position as a function of emission rate, whereas in high-resolution analysis, the emission rate peak position was measured at various fixed temperatures. Furthermore, the deeplevel trap concentration $\left(\mathrm{N}_{\mathrm{T}}\right)$ was determined using the formula [12]:

$$
N_{T}=2 N_{D} \Delta C / C_{0}
$$

where $\mathrm{C}_{0}$ is a capacitance of the Schottky diode at a fixed reverse bias and $\mathrm{N}_{D}$ is a net doping concentration of shallow levels, obtained from $\mathrm{C}-\mathrm{V}$ measurements. Calculated values of activation energy and capture cross section (in these studies assumed to be temperature independent) of electron traps E1, E2 and E3 observed in a low-temperature DLTS spectrum are collected in Table 1. Moreover, concentrations of traps, as extracted from DLTS-peak amplitudes for long enough filling pulses equal to $1 \mathrm{~ms}$ (ensuring that all the traps are really filled up, i.e. DLTS-peaks intensities are saturated), are collected in Table 2.

According to the data presented in Table 1, the deep-level position of the trap E1 varies significantly with varying nitrogen concentration in the range of $0.15 \mathrm{eV}$ to $0.24 \mathrm{eV}$, suggesting its attribution to the nitrogen-related defect in GaNAs. It is generally known, according to the BAC model [10], that the parameters of the N-related traps in dilute-nitrides are strongly dependent on the $\mathrm{N}$ content, due to the band gap reduction with incorporation of the $\mathrm{N}$ atoms into the crystal. They may also vary depending on the sample quality, growth method, and post-growth processing. 


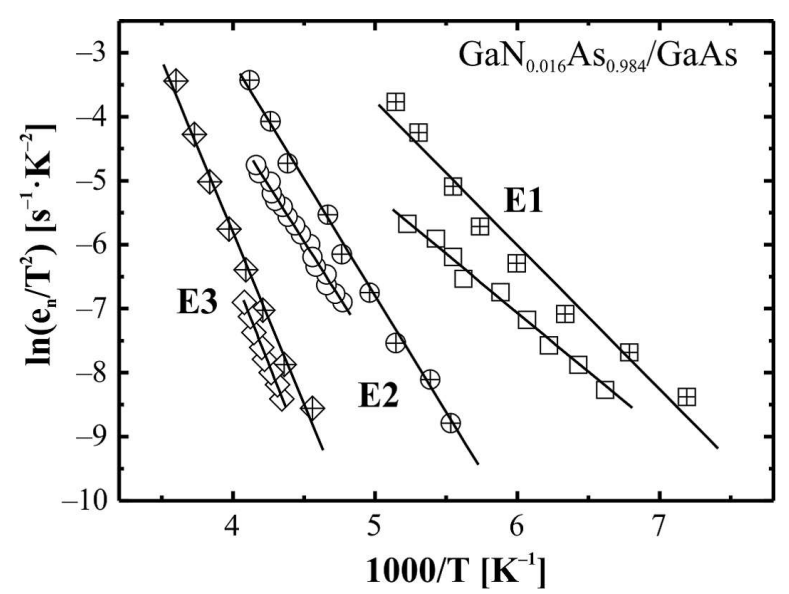

Fig. 4. The Arrhenius plots of the peaks E1, E2, E3 depicted in Fig. 2 and Fig. 3 for the $\mathrm{GaN}_{0.016} \mathrm{As}_{0.984} / \mathrm{GaAs}$ structure. Crossed points correspond to conventional DLTS analysis and open points to Laplace DLTS analysis.

According to theoretical predictions, the $\mathrm{N}$ complexes, such as nitrogen split interstitials $\mathrm{N}-\mathrm{As}$ and $\mathrm{N}-\mathrm{N}$ on single As sites are the dominant defects in GaNAs [23]. Experimental data confirm that the as-grown GaNAs layers contain a significant concentration of nitrogen interstitials [7, 24]. It is also known that formation of the $(\mathrm{N}-\mathrm{As})_{A s}$ complexes leads to compressive strain in the epilayer while the $(\mathrm{N}-\mathrm{N})_{\text {As }}$ complexes induce less tensile strain compared to the substitutional $\mathrm{N}_{\mathrm{As}}$ atom. Formation of the $\mathrm{N}$ complexes is mainly responsible for the observed significant deviation of the lattice parameter in GaNAs from the Vegard's law [25] and a low luminescence efficiency of as-grown $(\mathrm{Ga}, \mathrm{In})(\mathrm{N}, \mathrm{As})$ materials [7, 24]. Therefore, the E1 trap with the activation energy of 0.15 to $0.24 \mathrm{eV}$ was tentatively associated with one of such N complexes. Similar electron traps with comparable activation energies (depending on the $\mathrm{N}$ content) have been already observed in GaNAs grown by $\mathrm{MBE}$ [26, 27], CBE [16] as well as MOVPE [28].

On the contrary, the electron traps E2 and E3 maintain almost the same activation energies in all studied samples ranging from $0.30 \mathrm{eV}$ to $0.32 \mathrm{eV}$ and $0.48 \mathrm{eV}$ to $0.49 \mathrm{eV}$, respectively. The energy positions of these traps are very close to two commonly observed deep levels in a bulk and epitaxial GaAs, as well as GaAs-based structures grown by MOVPE, called EL6 and EL3, according to the Martin's et al. [29] classification scheme. These defects were previously observed also in the GaNAs and GaInNAs heterostructures [30]. The macroscopic structure of the EL3 is usually determined as the off-centre substitutional oxygen on the arsenic site $\left(\mathrm{O}_{\text {As }}\right)[31,32]$ or it is related to the As vacancy $\left(\mathrm{V}_{\mathrm{As}}\right)[33,34]$. On the other hand, EL6 is commonly associated with native complex defects involving arsenic antisite $\left(\mathrm{As}_{\mathrm{Ga}}\right)$ and electronically shallower center, as gallium or arsenic vacancy $\left(\mathrm{V}_{\mathrm{Ga}}, \mathrm{V}_{\mathrm{As}}\right)$ [33-35]. These defects are generally regarded by some authors as the possible candidates for major recombination centers in GaAsbased alloys $[33,36]$.

\subsection{High-temperature DLTS spectra}

A high-temperature DLTS spectrum consists of a weak positive peak E4, emerging near $370 \mathrm{~K}$ for all studied samples, as it is shown in Fig. 5. The energy position of the trap E4 is located at about $0.81 \mathrm{eV}$ below the conduction band for all studied samples. Furthermore, the density of the trap, calculated from the peak amplitude was also very similar and equal to about $2.0 \times 10^{13} \mathrm{~cm}^{-3}$ to $2.6 \times 10^{13} \mathrm{~cm}^{-3}$ (Table 2). High-resolution Laplace DLTS spectra, measured at $370 \mathrm{~K}$ (i.e. near the DLTS-peak maximum), are presented in the inset of Fig. 5. As it can be seen from this inset, the DLTS peak corresponds to the sharp Laplace DLTS peak, suggesting a mono-exponential emission process expected from a well-defined single energy level related to a point defect.

The corresponding Arrhenius plots obtained from conventional DLTS (crossed points) as well as Laplace DLTS (open points) measurements are shown in Fig. 6. The calculated trap parameters are collected in Table 3.

Similarly to the traps E2 and E3, also the trap E4 manifests the parameters comparable with another native point defect, commonly observed in GaAs and GaAs-based semiconductors, called EL2 [29]. The EL2 defect has been the most important and extensively studied deep-level defect in GaAs in the last two decades. It is generally 
Table 1. Activation energies $\left(\mathrm{E}_{\mathrm{a}}\right)$ and apparent capture cross sections $\left(\sigma_{\mathrm{a}}\right)$ obtained from conventional DLTS and Laplace DLTS analysis of the traps E1, E2 and E3 observed in $\mathrm{GaN}_{\mathrm{x}} \mathrm{As}_{1-\mathrm{x}} / \mathrm{GaAs}$ samples $(\mathrm{x}=1.2 \%$ to $2.7 \%)$ in low-temperature spectra $(<300 \mathrm{~K})$. In the last column, possible identities of the traps have been made on the basis of comparison with activation energies of the defects observed in as-grown GaAs and GaNAs, as reported in the references given below.

\begin{tabular}{cccccccccc}
\hline \multirow{2}{*}{ Trap label } & \multicolumn{2}{c}{$1.2 \% \mathrm{~N}$} & \multicolumn{4}{c}{ GaNAs/GaAs 1.6\% } & \multicolumn{2}{c}{$2.7 \% \mathrm{~N}$} & \multirow{2}{*}{ Possible identity } \\
\cline { 2 - 9 } & \multicolumn{2}{c}{ DLTS } & \multicolumn{2}{c}{ DLTS } & \multicolumn{2}{c}{ LDLTS } & \multicolumn{2}{c}{ DLTS } & \\
\cline { 2 - 8 } & $\mathrm{E}_{\mathrm{a}}[\mathrm{eV}]$ & $\sigma_{\mathrm{a}}\left[\mathrm{cm}^{2}\right]$ & $\mathrm{E}_{\mathrm{a}}[\mathrm{eV}]$ & $\sigma_{\mathrm{a}}\left[\mathrm{cm}^{2}\right]$ & $\mathrm{E}_{\mathrm{a}}[\mathrm{eV}]$ & $\sigma_{\mathrm{a}}\left[\mathrm{m}^{2}\right]$ & $\mathrm{E}_{\mathrm{a}}[\mathrm{eV}]$ & $\sigma_{\mathrm{a}}\left[\mathrm{cm}^{2}\right]$ & \\
\hline \hline $\mathrm{E} 1$ & 0.24 & $8.8 \times 10^{-18}$ & 0.21 & $2.9 \times 10^{-18}$ & 0.20 & $3.4 \times 10^{-18}$ & 0.15 & $2.1 \times 10^{-18}$ & N-related $^{\mathrm{a}-\mathrm{d}}$ \\
$\mathrm{E} 2$ & 0.32 & $1.7 \times 10^{-16}$ & 0.32 & $2.5 \times 10^{-16}$ & 0.30 & $6.6 \times 10^{-16}$ & 0.32 & $1.6 \times 10^{-16}$ & EL6 $^{\mathrm{e}-\mathrm{g}}$ \\
$\mathrm{E} 3$ & 0.49 & $3.9 \times 10^{-13}$ & 0.49 & $3.2 \times 10^{-14}$ & 0.48 & $1.5 \times 10^{-14}$ & 0.49 & $5.2 \times 10^{-14}$ & EL3 $^{\mathrm{f}-\mathrm{h}}$ \\
\hline
\end{tabular}

${ }^{\mathrm{a}}[16],{ }^{\mathrm{b}}[26],{ }^{\mathrm{c}}[27],{ }^{\mathrm{d}}[28],{ }^{\mathrm{e}}[36],{ }^{\mathrm{f}}[29],{ }^{\mathrm{g}}[34],{ }^{\mathrm{h}}[32]$

Table 2. Concentration of the electron traps E1, E2 and E3 obtained from DLTS measurements of the $\mathrm{GaN}_{\mathrm{x}} \mathrm{As}_{1-\mathrm{x}} / \mathrm{GaAs}$ samples $(\mathrm{x}=1.2 \%$ to $2.7 \%$ ).

\begin{tabular}{cccc}
\hline \multirow{2}{*}{ GaNAs/GaAs } & E1 (N-related) & E2 (EL6) & E3 (EL3) \\
\cline { 2 - 4 } & $\mathrm{N}_{\mathrm{T}}\left[\mathrm{cm}^{-3}\right]$ & $\mathrm{N}_{\mathrm{T}}\left[\mathrm{cm}^{-3}\right]$ & $\mathrm{N}_{\mathrm{T}}\left[\mathrm{cm}^{-3}\right]$ \\
\hline \hline $1.2 \% \mathrm{~N}$ & $1.3 \times 10^{13}$ & $2.1 \times 10^{13}$ & $1.1 \times 10^{13}$ \\
$1.6 \% \mathrm{~N}$ & $1.8 \times 10^{13}$ & $4.5 \times 10^{13}$ & $4.2 \times 10^{13}$ \\
$2.7 \% \mathrm{~N}$ & $1.6 \times 10^{13}$ & $7.0 \times 10^{13}$ & $4.5 \times 10^{13}$ \\
\hline
\end{tabular}

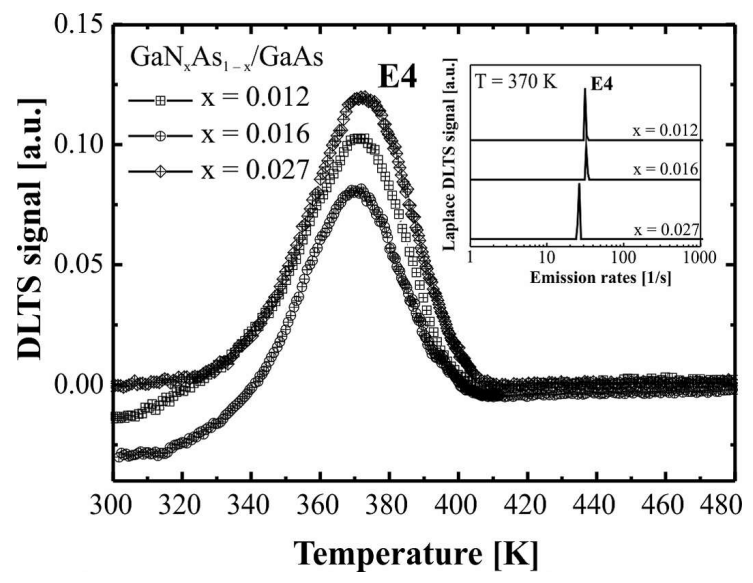

Fig. 5. High-temperature DLTS spectra obtained for the $\mathrm{GaN}_{\mathrm{x}} \mathrm{As}_{1-\mathrm{x}} / \mathrm{GaAs}$ heterostructures with different nitrogen contents $(\mathrm{x})$. The inset shows corresponding LDLTS spectra recorded at $370 \mathrm{~K}$.

considered that EL2 level is related to the isolated arsenic antisite defect $\left(\mathrm{As}_{\mathrm{Ga}}\right)$ or defect complex involving $\mathrm{As}_{\mathrm{Ga}}$ with interstitials and/or vacancies $\left(\mathrm{As}_{\mathrm{i}}, \mathrm{V}_{\mathrm{As}}, \mathrm{V}_{\mathrm{Ga}}\right)[34,37]$ and its formation is favorable under the As-rich conditions. The EL2 defect

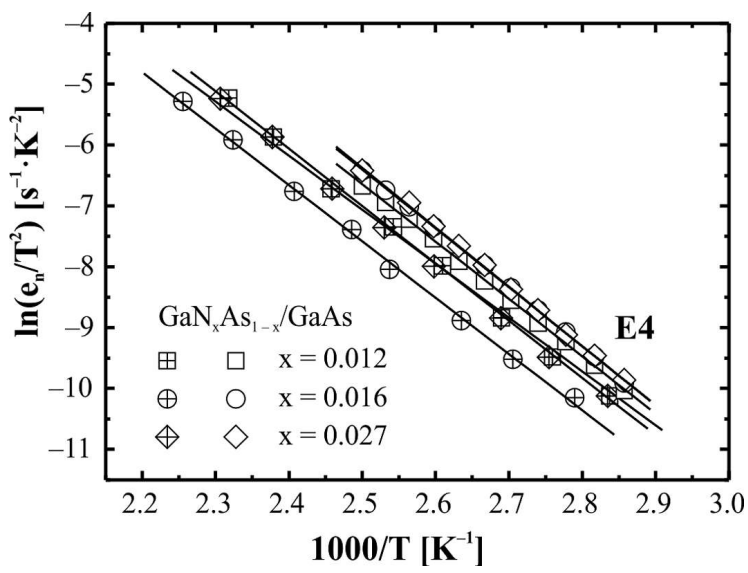

Fig. 6. The Arrhenius plots of the peak E4 for all studied samples. Crossed points correspond to conventional DLTS analysis and open points to Laplace DLTS analysis.

is also commonly observed in GaNAs and GaInNAs layers grown by different techniques $[6,14$, 27, 30].

In order to correlate the revealed deep levels with electrical and optical properties of the GaNAs/GaAs structures, more detailed studies are required. In the near future, we are planning to perform successive electrical and optical measurements on as-grown as well as annealed samples, which should provide sufficient information about a real nature of the deep-level defects observed in our samples and their possible influence on the parameters of future GaNAs-based devices obtained by means of APMOVPE technique. 
Table 3. Activation energy $E_{a}$, apparent capture cross section $\sigma_{a}$ and concentration $N_{T}$ obtained from the conventional DLTS and Laplace DLTS analysis of the trap E4 observed in the $\mathrm{GaN}_{\mathrm{x}} \mathrm{As}_{1-\mathrm{x}} / \mathrm{GaAs}$ samples $(\mathrm{x}=$ $1.2 \%$ to $2.7 \%$ ) in high-temperature spectra ( $>300 \mathrm{~K}$ ). In the last column, possible identity of the trap has been proposed.

\begin{tabular}{|c|c|c|c|c|c|c|}
\hline \multirow{3}{*}{ GaNAs/GaAs samples } & \multicolumn{5}{|c|}{ E4 (EL2) } & \multirow{3}{*}{ Possible identity } \\
\hline & \multicolumn{3}{|c|}{ DLTS } & \multicolumn{2}{|c|}{ LDLTS } & \\
\hline & $\mathrm{N}_{\mathrm{T}}\left[\mathrm{cm}^{-3}\right]$ & $\mathrm{E}_{\mathrm{a}}[\mathrm{eV}]$ & $\sigma_{\mathrm{a}}\left[\mathrm{cm}^{2}\right]$ & $\mathrm{E}_{\mathrm{a}}[\mathrm{eV}]$ & $\sigma_{\mathrm{a}}\left[\mathrm{cm}^{2}\right]$ & \\
\hline $1.2 \% \mathrm{~N}$ & $2.3 \times 10^{13}$ & 0.81 & $2.4 \times 10^{-14}$ & 0.817 & $7.7 \times 10^{-14}$ & \\
\hline $1.6 \% \mathrm{~N}$ & $2.0 \times 10^{13}$ & 0.80 & $1.2 \times 10^{-14}$ & 0.80 & $3.8 \times 10^{-14}$ & $\mathrm{EL} 2^{\mathrm{a}-\mathrm{c}}$ \\
\hline $2.7 \% \mathrm{~N}$ & $2.6 \times 10^{13}$ & 0.81 & $1.9 \times 10^{-14}$ & 0.80 & $2.3 \times 10^{-14}$ & \\
\hline
\end{tabular}

${ }^{\mathrm{a}}[29],{ }^{\mathrm{b}}[34],{ }^{\mathrm{c}}[37]$

\section{Conclusions}

In this paper, the electrical properties of deeplevel defects observed in epitaxial GaNAs/GaAs heterostructures grown by APMOVPE at different nitrogen concentrations $(1.2 \%$ to $2.7 \%)$ were investigated. Combination of conventional DLTS and high-resolution Laplace DLTS techniques makes possible to resolve all the deep levels in the band gap and to calculate their electrical parameters. The electron trap E1 with activation energy ranging from $0.15 \mathrm{eV}$ to $0.24 \mathrm{eV}$ (depending on the $\mathrm{N}$ content) is most likely connected with the N-related complexes, such as nitrogen split interstitial defects. On the other hand, the other traps labeled E2, E3 and E4, with deep levels located at about $0.32 \mathrm{eV}, 0.49 \mathrm{eV}$ and $0.81 \mathrm{eV}$ below the conduction band edge, are associated with commonly known GaAs-like native defects and impurities called EL6, EL3 and EL2, respectively.

\section{Acknowledgements}

This work was financed by Polish Ministry of Science and Higher Education under the Grant No. N N507 552938.

\section{References}

[1] Geisz J.F., Friedman D.J., Semicond. Sci. Tech., 17 (2002), 769.

[2] Kurtz S.R., Allerman A.A., Jones E.D., GeE J.M., Banas J.J., Hammons B.E., Appl. Phys. Lett., 74 (1999), 729.

[3] Kondow M., Uomi K., Niwa A., Kitatani T., Watahiki S., Yazawa Y., Jpn. J. Appl. Phys., 35 (1996), 1273.
[4] Fischer M., Gollub D., Reinhardt M., KAMP M., Forchel A., J. Cryst. Growth, 251 (2003), 353.

[5] ŚCIANA B., ZBorowsKa-Lindert I., PUCICKI D., BORATYŃSKI B., RADZIEWICZ D., TŁaczaŁa M., Serafińczuk J., Poloczek P., SĘK G., Misiewicz J., Opto-Electron. Rev., 16 (2008), 1.

[6] Buyanova I.A., Chen W.M., Tu C.W., J. Phys.Condens. Mat., 16 (2004), S3027.

[7] Li W., Pessa M., Ahlgren T., Dekker J., Appl. Phys. Lett., 79 (2001), 1094.

[8] Khan A., Kurtz S.R., Prasad S., Johnston S.W., Gou J., Appl. Phys. Lett., 90 (2007), 243509.

[9] ŚCIANA B., RADZIEWICZ D., PuCICKI D., ZborowsKa-Lindert I., SERAFIŃCZUK J., TŁaczaŁa M., Latkowska M., Kováč J., SRNANEK R., Cryst. Res. Technol., 47 (2012), 313.

[10] Shan W., Walukiewicz W., Ager III J.W., Haller E., Geisz J.F., Friedman D.J., Olson J.M., Kurtz S.R., Phys. Rev. Lett., 82 (1999), 1221.

[11] Kamyczek P., Biegański P., PŁaczek-Popko E., ZiElony E., GelCZUK Ł., ŚCIANA B., PUCICKI D., Radziewicz D., TŁaCZaŁa M., Kopalko K., DąBROWSKA-SzATA M., Mater. Sci.-Poland, 31 (2013), 595.

[12] Blood P., Orton J.W., Characterization of Semiconductors: Majority Carriers and Electron States, Academic Press, London, 1992.

[13] Johnston S.W., Kurtz S.R., Friedman D.J., Ptak A.J., Ahrenkiel R.K., Crandall R.S., Appl. Phys. Lett., 86 (2005), 072109.

[14] Tanaka S., Moto A., Takahashi M., Tanabe T., TAKAGISHI S., J. Cryst. Growth, 221 (2000), 467.

[15] Krispin P., Spruette S.G., Harris J.S., Ploog K.H., J. Appl. Phys., 88 (2000), 4153.

[16] Bouzazi B., Suzuki H., Kojami N., Ohsita Y., Yamaguchi M., Physica B, 406 (2011), 1070.

[17] Geisz J.F., Friedman D.J., Olson J.M., Kurtz S.R., KeYes B.M., J. Cryst. Growth, 195 (1998), 401.

[18] Moto A., Takahashi M., Takagishi S., J. Cryst. Growth, 221 (2000), 485. 
[19] Kaplar R.J., Kwon D., Ringel S.A., Allerman A.A., Kurtz S.R., Jones E.D., Sieg R.M., Sol. Energ. Mat. Sol. C., 69 (2001), 851.

[20] GelczuK Ł., Stokowski H., DąrowskaSzata M., Kudrawiec R., J. Appl. Phys., 119 (2016), 185706.

[21] Gelczuk Ł., Dąbrowska-Szata M., Pucicki D., Acta Phys. Pol. A, 126 (20014), 1195.

[22] Dobaczewski L., Peaker A.R., BondeNielsen K., J. Appl. Phys., 96 (2004), 4689.

[23] Zhang S.B., WeI S.-H., Phys. Rev. Lett., 86 (2001), 1789.

[24] Spruytte S.G., Coldren C.W., Harris J.S., WAMPler W., Krispin P., PloOG K., LARSON M.C., J. Appl. Phys., 89 (2001), 4401.

[25] Li W., Pessa M., Likonen J., Appl. Phys. Lett., 78 (2001), 2864.

[26] Krispin P., Gambin V., Harris J.S., Ploog K.H., J. Appl. Phys., 93 (2003), 6095.

[27] Shafi M., Mari R.H., Henini M., Taylor D., Hopkinson M., Phys. Status Solidi C, 6 (2009), 2652.

[28] Johnston S.W., Kurtz S.R., J. Vac. Sci. Technol. A, 24 (2006), 1252.

[29] Martin G.M., Mitonneau M., Mircea A., Electron. Lett., 13 (7) (1977), 191.
[30] Polyakov A.Y., Smirnov N.B., Govorkov A.V., BotchKarev A.E., Nelson N.N., FAhMi M.M.E., GrifFin J.A., Khan A., MOHAMmad S.N., JOHNStone D.K., Bublik V.T., ChSherbatcheV K.D., Voronova M.I., KasatochKin V.S., Solid State Electron., 46 (2002), 2155.

[31] Skowronski M., Mater. Sci. Forum, 83 - 87 (1992), 377.

[32] Wohlrab A., Grundig-Wendrock B., JURISCH M., KiESSLING F.-M., NikLas J.R., Eur. Phys. J.-Appl. Phys., 27 (2004), 223.

[33] Reddy C.V., Fung S., Beling C.D., Phys. Rev. B, 54 (1996), 11290.

[34] Bourgoin J.C., von Bardeleben H.J., StiéveNARD D., J. Appl. Phys., 64 (1988), R65.

[35] ShIRAKi H., Tokuda Y., SAssa K., J. Appl. Phys., 84 (1998), 3167.

[36] Fang Z.-Q., Schlesinger T.E., Milnes A.G., J. Appl. Phys., 61 (1987), 5047.

[37] Kamińska M., Weber E.R., EL2 Defect in GaAs, in: WEBER E.R. (Ed.), Imperfections in III/V Materials, Semiconductors and Semimetals, Vol. 8, Academic Press, Boston, 1993, p. 59.

Received 2015-12-18 Accepted 2016-11-02 